\title{
(t)
}

\section{O FINANCIAMENTO DA SAÚDE NO BRASIL: PRINCIPAIS DILEMAS}

The financing of health in Brazil: principal dilemmas

\author{
Tainá Souza Conceição' \\ Juliana Fiúza Cislaghi \\ Sandra Oliveira Teixeira ${ }^{3}$
}

\section{RESUMO}

O texto apresenta os principais dilemas postos ao financiamento da saúde no Brasil. Após o resgate da construção do orçamento da seguridade social, analisa-se o financiamento para a saúde, com seus dilemas e embates desde a construção da Emenda Constitucional 29 e a luta pela sua regulamentação até a proposta de contrarreforma tributária. Diante do histórico subfinanciamento do Sistema Único de Saúde (SUS), que impossibilita a universalização do acesso e a qualidade na prestação dos serviços de saúde, as respostas que vêm sendo dadas por setores, principalmente governistas, são de que aquele representa um problema de gestão e não de falta de recursos. Tal posicionamento deu origem às propostas dos "novos" modelos na gestão da saúde, combatidos por diversos atores políticos, que defendem a ampliação de recursos para o SUS.

\footnotetext{
${ }^{1}$ Mestre em Serviço Social, Professora Assistente da Faculdade de Serviço Social da UERJ e Pesquisadora do GOPSS/UERJ.. E-mail: <taina.con@gmail.com>.

2 Mestre em Serviço Social, Professora Assistente da Faculdade de Serviço Social da UERJ e Coordenadora do GOPSS/UERJ. E-mail: <fiuzajuliana@yahoo.com.br>. 3 Mestre em Política Social. Professora Assistente Departamento de Serviço Social da UnB e Pesquisadora do GOPSS/UERJ. E-mail: <sandrinhateixeira@gmail.com>.
} 


\section{PALAVRAS-CHAVE}

Financiamento do SUS. Privatização do SUS. Novos Modelos de Gestão. Emenda Constitucional 29.

\section{ABSTRACT}

The following paper presents the main dilemmas in Brazilian health funding. After the retake of the social security's budget construction, health funding is analyzed, with its dilemmas and conflicts which are in place since Constitutional Amendment 29 and the struggle for its regulation to the proposal for a tax counter-reform. Given the SUS sub-funding history, which precludes the universalization of health services access and quality, the answers that have been given by sectors, mainly the government, is that it is a management problem, not created by the lack of resources. Those positions developed proposals for "New" Management Models in Healthcare, which are contested by several political actors, defending the resources expansion for SUS.

\section{KEYWORDS}

SUS Funding. SUS Privatization. New Management Models. Constitutional Amendment 29.

\section{INTRODUÇÃO}

Este texto tem por objetivo analisar o financiamento da saúde brasileira e suas perspectivas diante de um contexto de fortes constrangimentos impostos ao orçamento da seguridade social. É preciso esclarecer desde o início que consideramos o orçamento público não apenas como uma peça técnica que explícita as fontes de financiamento e as despesas apresentadas pelo Poder Executivo e aprovadas pelo Poder Legislativo. Ele é, sobretudo, uma arena de embate político de diferentes sujeitos que interferem na origem e no destino de recursos em função de interesses de classes e de grupos sociais. 
Em que consiste essa disputa do orçamento público no capitalismo? O fundo público, que abrange o orçamento público - questão tributária, política monetária, entre outros instrumentos da política econômica e de desenvolvimento capitalista -, é fruto da correlação de forças estabelecidas entre as classes sociais. Não deve ser apreendido como a manifestação de recursos unicamente para financiar a acumulação do capital ou exclusivamente para reproduzir a força de trabalho (OLIVEIRA, 1998). Nessa disputa, verifica-se um movimento

[...] em que a mobilização dos trabalhadores busca garantir o uso da verba pública para o financiamento de suas necessidades, expressas em políticas públicas. Já para o capital, com sua força hegemônica, consegue assegurar a participação do Estado em sua reprodução por meio de políticas de subsídios econômicos, de participação no mercado financeiro, com destaque para a rolagem da dívida pública (BEHRING; BOSCHETTI, 2006, p. 174).

O fato é que, em tempos de primazia do capital financeiro e da crise do capital, a disputa do fundo público entre o capital e o trabaIho tornou-se mais acirrada e profundamente desigual. O capital vem sendo cada vez mais privilegiado em detrimento do trabalho, em razão, especialmente, da financeirização da dívida pública e da diversidade de estratégias adotadas na privatização de serviços públicos, nichos lucrativos cada vez mais rentáveis.

Com base nessas considerações, inicialmente, este trabalho apresenta de forma sucinta os orçamentos que compõem o Orçamento Geral da União, detendo-se especificamente no orçamento da seguridade social e no debate da regressividade de suas fontes de financiamento. Em seguida, analisamos o subfinanciamento da seguridade social, especialmente o da saúde, e as ameaças ao orçamento desse modelo de proteção social com destaque para a contrarreforma tributária. A quinta parte trata dos dilemas da descentralização e da privatização por dentro do SUS, referentes: a) à centralização de arrecadação tributária na União, embora esta tenha sido a esfera que menos ampliou os investimentos na saúde; e b) à adoção da contratação de serviços no âmbito privado. Aborda-se, então, a proposta de regulamentação da Emenda 
29 e de criação da Contribuição Social para a Saúde (CSS). Ao final, questiona-se o lugar que os novos modelos de gestão público-privada assumem no âmbito da política de saúde, quanto à sua racionalização, ampliação e agilização do atendimento ou apropriação do fundo público.

\section{O ORÇAMENTO DA SEGURIDADE SOCIAL NA CONSTITUIÇÃO DE 1988}

A Constituição de 1988 estruturou o orçamento do Estado brasileiro em três esferas: o orçamento fiscal, o orçamento das estatais e o orçamento da Seguridade Social. O Orçamento de Investimentos das Estatais (OI) refere-se às empresas em que a União detém, direta ou indiretamente, a maioria do capital social com direito a voto. Este orçamento demonstra apenas pequena parcela dos recursos das empresas estatais federais, tendo em vista que abrange somente os investimentos realizados no interior dessas empresas e não a totalidade dos recursos geridos por elas ${ }^{4}$.

O orçamento fiscal é composto pelos impostos, sendo o mais importante o imposto de renda, e seus gastos são direcionados a um conjunto de políticas públicas, tais como: defesa nacional, judiciário, educação, administração, trabalho, habitação, cultura, agricultura, transporte, indústria, comunicação, pagamento da dívida pública, dentre outras. Em suma, abrange todas as políticas setoriais do Estado, exceto aquelas que compõem a seguridade social.

A seguridade social, resultante da Constituição de 1988, é composta pelas políticas de saúde, previdência e assistência social, bem como a proteção ao trabalhador desempregado, incluindo

4 Recorremos ao exemplo do Banco Nacional do Desenvolvimento Social (BNDES) para mostrar o quão é turvo o orçamento das estatais. No ano de 2009, segundo consta no orçamento de investimentos, o BNDES investiu o montante de $\mathrm{R} \$$ 17,4 milhões em reformas, manutenção e aquisição de imóveis. Contudo, o BNDES, neste ano, apresentou o seguinte desempenho financeiro: o Sistema BNDES registrou lucro de $\mathrm{R} \$ \mathrm{6}, 7$ bilhões, fruto do expressivo crescimento das carteiras de operação de crédito e de títulos e valores mobiliários; o patrimônio líquido totalizou $\mathrm{R} \$$ 27,6 bilhões, correspondendo a um patrimônio de referência de $\mathrm{R} \$ 54$ bilhões; e os ativos totais do Sistema BNDES somaram R\$386,6 bilhões (BNDES, 2010). 
o seguro desemprego. Possui um orçamento próprio, composto, além das contribuições previdenciárias, por recursos orçamentários destinados exclusivamente a esse fim, num modelo que chamamos de vinculação de receitas. A Constituição prevê ainda que, de acordo com as necessidades, o orçamento da seguridade social pode ser complementado pelos recursos do orçamento fiscal.

Os recursos orçamentários vinculados ao orçamento da seguridade social são as contribuições sociais ${ }^{5}$. Elas representaram entre 2000 e 2007 , em média, $90 \%$ do total de recursos da seguridade social (SALVADOR, 2010), demonstrando a pouca participação dos recursos do orçamento fiscal no período. Dentre elas, as mais significativas são as Contribuições previdenciárias (média de 45,52\% de participação entre 2000 e 2007), a Contribuição Social sobre o Lucro Líquido (CSLL) (média de 6,88\%) e a Contribuição Social para o Financiamento da Seguridade Social (COFINS) (média de 26,28\%) .

O legislador procurou dar estabilidade ao padrão de financiamento, ao eleger várias fontes de recursos. Essa variedade de fontes de recursos da seguridade foi uma conquista importante, pois quando essas políticas eram exclusivamente financiadas pela folha de salários ficavam vulneráveis em períodos de desemprego, gerando queda do rendimento médio dos trabalhadores e aumento do número de trabalhadores sem vínculo formal de trabalho. Assim, a Constituição de 1988 inovou reduzindo a dependência do financiamento das políticas da seguridade da arrecadação da receita previdenciária, sujeita às oscilações da economia, passando a tributar o faturamento e o lucro - base de cálculo mais estável que a folha salarial (GENTIL, 2007).

Entretanto, ao adentrar na década de 1990, a política propagandista e falaciosa de crise do Estado vai se espraiar e se tornar terreno fértil para as políticas neoliberais, consolidadas no go-

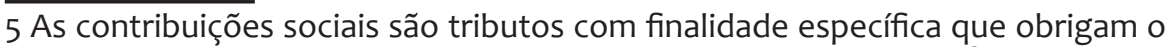
Estado a aplicá-las no destino estabelecido no momento em que foram criadas (SALVADOR, 2010, p. 236).

6 Até ser extinta a Contribuição Provisória sobre Movimentação Financeira (CPMF), também foi uma importante fonte de recursos da Seguridade, chegando a representar $10 \%$ dos recursos totais, em 2000. Voltaremos à CPMF, mais a frente. 
verno Cardoso. A situação do financiamento da seguridade social revela, na perspectiva dos trabalhadores e das necessidades sociais reais, uma lógica perversa na alocação do fundo público no Brasil. Hoje, mais do que nunca, o que está em jogo é o redirecionamento do fundo público, escasseando sua alocação na composição das políticas públicas e participando ativamente na recomposição da rentabilidade do capital (BEHRING, 2008).

Dentro da lógica atual, são os beneficiários diretos das políticas da seguridade social - isto é, os trabalhadores -, em grande medida, os próprios financiadores destas políticas, mediante o pagamento de impostos. Isso porque o sistema tributário brasileiro é regressivo, ou seja, baseado em tributos indiretos que não aumentam proporcionalmente, conforme aumenta a renda das famílias, e são repassados à população no preço de produtos e serviços consumidos. Segundo dados do Instituto Brasileiro de Geografia e Estatística (IBGE) referentes a 2002/2003, as famílias com renda de até 2 salários mínimos arcam em tributos indiretos o equivalente a $46 \%$ da sua renda familiar, enquanto famílias com renda de mais de 30 salários mínimos gastam $16 \%$ da sua renda com tributos indiretos (SALVADOR, 2008). Como podemos ver no Gráfico 1, quase metade dos tributos, em 2009, recaiu sobre o consumo, ficando em segundo lugar a incidência sobre a folha de salários e em terceiro lugar sobre a renda. Outras incidências, como o patrimônio, são a menor base de tributação do país.

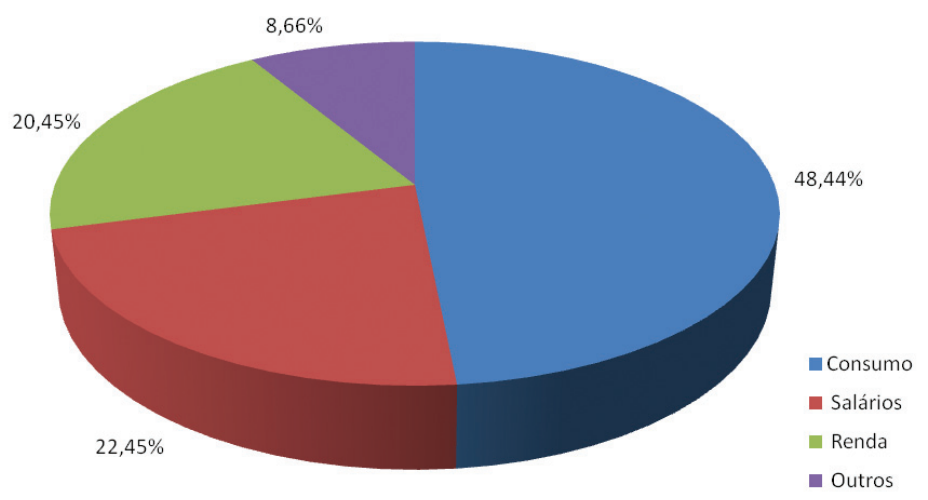

Gráfico 1: Tributos por base de incidência - 2009. Elaboração própria.

Fonte: Imposto... (2009). 


\section{AS CONTRARREFORMAS NEOLIBERAIS E O SUBFINANCIAMENTO DA SEGURIDADE SOCIAL}

Além de o fundo público brasileiro ser hoje composto majoritariamente pela renda dos trabalhadores, devido à regressividade do nosso sistema tributário, desde os anos 90, os gastos sociais estão cada vez mais direcionados a políticas para o capital, e não para os trabalhadores. A crise do capitalismo mundial, em curso desde os anos de 1970 e marcada pela queda tendencial das taxas de lucro, levou o capital a disputar cada vez mais os recursos do fundo público. Duas características passam a marcar o campo dos direitos e serviços sociais: (a) um progressivo aumento da privatização na saúde, na educação, na previdência, dentre outros - o que, por sua vez, significou uma ampliação do espaço para investimentos lucrativos do capital; e (b) um também progressivo subfinanciamento das políticas sociais públicas, reduzindo a aplicação do fundo público em seus orçamentos. Com isso, o fundo público passou a ser direcionado para políticas que beneficiam o capital, como é o caso do pagamento da dívida pública, cujos títulos estão nas mãos do grande capital, ou seja, em bancos e fundos de pensão. O Estado passou assim a ser uma espécie de Robin Hood às avessas, que tira a renda dos trabalhadores para repassá-la aos grandes capitalistas.

Behring (2008) indica a tendência de crescimento vegetativo no financiamento da seguridade social, que tem girado em torno de $12 \%$ do Produto Interno Bruto (PIB), o que denota aquilo que a autora chama de ausência de saltos efetivos, no que tange à alocação de recursos para a seguridade social. Com relação à evolução da carga tributária no Brasil, por sua vez, tem-se um crescimento substancial, principalmente quando se leva em conta que em 1947 a carga tributária brasileira representava 13,8\% do PIB e em 2010 esse percentual chegou a 35,13\% do PIB (ALVARENGA, 2010). Contudo, tal crescimento não resulta em crescimento real para o financiamento das políticas da seguridade social.

O Gráfico 2 - elaborado pela Auditoria Cidadã da Dívida -, tendo 2010 como ano-base, demonstra que a maior parte do orçamento federal está comprometida com o pagamento de juros e amortizações da dívida pública. Entre as políticas públicas, apenas a previdência social representa uma parte significativa do orçamento, 
pois seus benefícios devem obrigatoriamente ser pagos de acordo com as regras legais. É graças a isso que os governos têm feito tantos esforços para aprovar contrarreformas que reduzam o direito dos trabalhadores aos benefícios previdenciários.

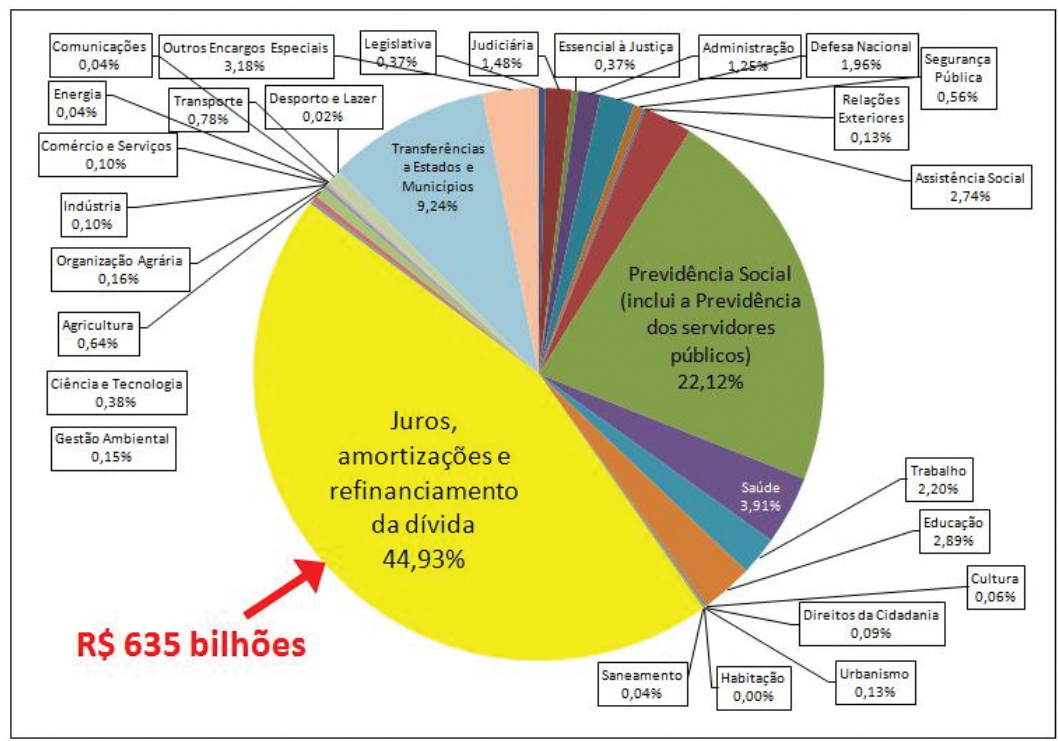

Gráfico 2: Orçamento Geral da União por Função - Ano 2010 Fonte: Elaboração: Auditoria Cidadã da Dívida (2010).

Já a política de saúde conta apenas com 3,91\% do orçamento federal total. Outras políticas, como educação (2,89\%), assistência social (2,74\%, incluindo os gastos com o Bolsa Família) e habitação (0,00\%), têm participação ainda mais ínfima no orçamento, demonstrando que a prioridade do governo é o pagamento de juros da dívida ao grande capital credor, ampliando a dívida social com a população trabalhadora.

O Gráfico 3, deflacionado com base no Índice Geral de Preços-Disponibilidade Interna (IGP-DI) em 2009, demonstra os gastos do governo federal em saúde, desde a implementação do SUS. Podemos notar inicialmente um incremento nos recursos para cobrir a ampliação da cobertura decorrente da universalização do sistema. Depois desse momento, porém, os recursos ficam estagnados numa faixa entre 40 e 50 bilhões de reais, tendo sido financiados, principalmente, pela CPMF até a sua extinção e pela Contribuição Social sobre o Lucro Líquido (CSLL). Conforme vimos, isso reflete não só a 
disputa por recursos dentro da seguridade social, mas, sobretudo, uma estagnação na totalidade dos recursos do orçamento da seguridade, apesar do governo ter ampliado a arrecadação de tributos nesse período. Entre 1996 e 2005, a arrecadação tributária aumentou 101,62\% (SALVADOR, 2007).

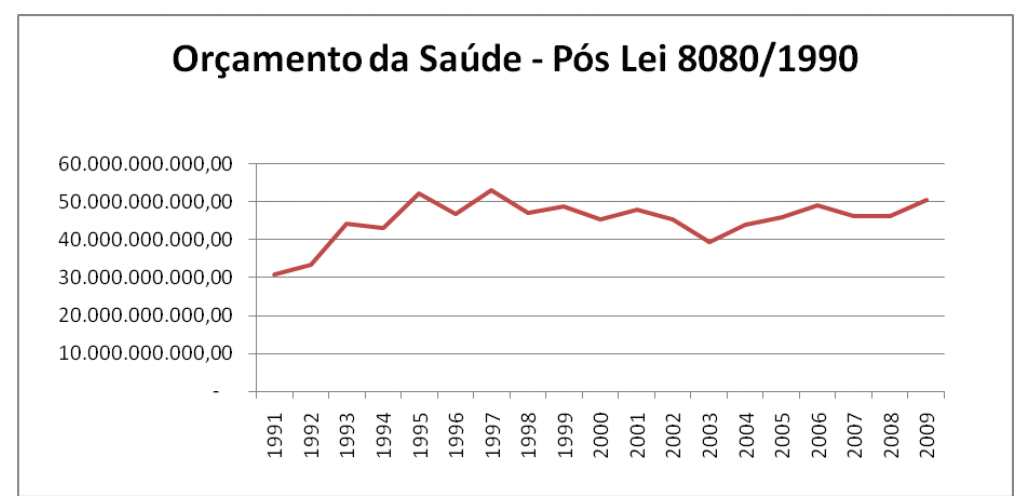

Gráfico 3: Orçamento da saúde - pós Lei 8.080, de 1990 (em Reais).

Fonte: Banco de dados do Tesouro Nacional. Elaboração própria. Corrigido pelo IGP-DI.

Quanto ao valor destinado ao SUS pelos três entes federados, o referido montante não ultrapassa o limite de 3,7\% do PIB. No Brasil, o gasto total da saúde, pública e privada, gira em torno de $8 \%$ do PIB, sendo que a participação pública é de apenas $42 \%$. Ou seja, trata-se de um país onde, mesmo tendo um sistema público universal de saúde, o gasto privado (salário de trabalhadores cidadãos) é maior que o público (PIOLA, [2009]).

Uma questão se impõe: por que o aumento da arrecadação das contribuições sociais em âmbito federal não significou ampliação dos recursos para a seguridade social? Isto se deu devido à existência de um mecanismo de transferência dos recursos da seguridade social para o pagamento da dívida pública, a Desvinculação de Receitas da União (DRU) ${ }^{7}$, que permite que $20 \%$ dos recursos vinculados, não só no caso da seguridade, mas também no da educação, passem para o orçamento fiscal, permitindo que o governo os utilize para qualquer fim. Estima-se que a desvinculação de recursos retirou, entre 2000 e 2007 , o valor de 278,4 bilhões de reais

7 Antes de chamar-se DRU era denomina Fundo Social de Emergência (FSE) e Fundo de Estabilização Fiscal (FEF). 
da Seguridade Social, corrigidos pelo IGP-DI (SALVADOR, 2010, p. 377). Apesar da inconstitucionalidade da medida, em 2007, o Senado Federal aprovou a prorrogação da DRU até $2011^{8}$, reduzindo a desvinculação para 10\% em 2009 e $5 \%$ em 2010. Assim, ao invés de o orçamento fiscal complementar os recursos da seguridade social, a DRU faz o movimento contrário, retirando recursos da seguridade. Os recursos transferidos do orçamento fiscal para a seguridade social representam apenas $58 \%$ da transferência feita em sentido inverso, entre 2000 e 2007.

A DRU tornou-se fundamental na composição do superavit primário, este também saqueador do orçamento da seguridade social e das contas públicas. Criado em 1999, como mecanismo de ajuste das contas públicas e a serviço do pagamento da dívida - apesar de não cobri-la -, a estratégia de superavit primário tem montantes superiores aos gastos realizados com saúde e assistência social (BEHRING, 2008).

Além disso, as despesas da seguridade social, assim como ocorre nas ações de saúde, estão infladas com gastos que deveriam ser do orçamento fiscal, como a assistência e a previdência dos servidores públicos, mais a previdência e a saúde das Forças Armadas, reduzindo ainda mais seus recursos.

Outro mecanismo que materializou a retirada de recursos da seguridade social e das demais políticas sociais foi a Lei de Responsabilidade Fiscal (LRF), de 2000. A LRF limita as despesas não financeiras do orçamento e prioriza o pagamento de juros. Os governos passam a ter parâmetros rígidos para o cumprimento de metas fiscais que garantam o pagamento da dívida pública com os credores do grande capital, sem haver metas de redução de desigualdades sociais ou avaliação da necessidade de ampliação de recursos nas políticas sociais. Os recursos da área social passam, assim, a ficar submetidos às necessidades da área fiscal. A responsabilidade fiscal tem a irresponsabilidade social como sua contraface. Uma das principais consequências da LRF foi a limitação na contratação de pessoal, que significou a redução de concursos públicos e a

8 No final de 2011 foi votada pelo Congresso a prorrogação da DRU até 2015. 
falta de força de trabalho na saúde, na educação e nos demais serviços públicos, nos últimos anos.

Já a Contribuição Provisória sobre Movimentação ou Transmissão de Valores e de Créditos e Direitos de Natureza Financeira (CPMF), instituída por meio da Lei 9.311, de 1996, foi uma fonte de recursos da saúde que ganhou importância durante sua vigência. Prorrogada inúmeras vezes, a CPMF acabou em 2007. Nesse ano, segundo estimativa do governo, sua arrecadação foi de $\mathrm{R} \$ 14,7$ bilhões. Apesar disso, a CPMF também era um imposto regressivo que não seria necessário, caso se acabasse com a DRU, que, conforme já mencionado, foi prorrogada até 2015.

\section{A AMEAÇA DA CONTRARREFORMA TRIBUTÁRIA}

Outra ameaça que tem pairado sobre a seguridade social é a proposta de reforma tributária apresentada ainda no governo Lula: o Projeto de Emenda Constitucional (PEC) n²33, de 2008.

As principais propostas da PEC são a criação de um imposto sobre valor adicionado, com a extinção de quatro tributos federais: Contribuição para o Financiamento da Seguridade Social (COFINS), Programa de Integração Social (PIS), Contribuição de Intervenção no Domínio Econômico (CIDE) incidente sobre a importação e comercialização de combustíveis e a Contribuição social salário-educação), incorporação da CSLL ao Imposto de Renda da Pessoa Jurídica (IRPJ), redução gradativa da contribuição de empregadores à Previdência Social (o que vai significar uma perda de 24 milhões de reais para a Previdência), unificação da legislação do Imposto sobre a Circulação de Mercadorias e Serviços (ICMS) para todos os estados da federação, criação de um Fundo de Equalização de Receitas (FER) para compensar eventuais perdas de ICMS dos estados e criação de um Fundo Nacional de Desenvolvimento Regional (SALVADOR, 2008).

A justificativa do governo é que a proposta simplificaria os tributos e colocaria fim à guerra fiscal entre os estados, ou seja, à disputa de investimentos através de benefícios concedidos pela legislação própria do ICMS.

A proposta, porém, acaba com a lógica de vinculação das contribuições ao orçamento da seguridade social - na prática, acabando 
com seu orçamento próprio. O novo modelo proposto cria um imposto centralizado, o Imposto sobre Valor Adicionado (IVA), que, somado aos recursos do Imposto de renda e do Imposto sobre Produtos Industrializados (IPI), será dividido da seguinte forma: 38,8\% para a seguridade social, 2,3\% para a educação básica e 6,7\% para o seguro-desemprego, incluindo o PIS, que também terá sua contribuição social extinta.

Desse modo, fica sepultada a diversidade da base de financiamento da seguridade, que volta a depender da folha de salários. Outra consequência é a transformação do modelo de vinculação em modelo de partilha. E, portanto, a seguridade social passa a ter que disputar recursos do orçamento com estados e municípios, já que a base orçamentária passa a ser a mesma. Se com a vinculação o governo já conseguia construir subterfúgios para diminuir os recursos da seguridade, na lógica de partilha a disputa e a pressão tendem a ser maiores, dificultando mais ainda a recomposição do orçamento da seguridade social.

As mudanças a serem efetivadas na estrutura tributária brasileira para caminhar no sentido da distribuição de renda devem desonerar as famílias mais pobres e reafirmar o princípio constitucional que prevê que cabe a cada cidadão contribuir para o fundo público, de acordo com sua capacidade, ou seja, numa perspectiva progressiva. A proposta de (contra)reforma tributária em discussão não resolve esses problemas e ainda prejudica o financiamento da seguridade social, que perde suas já tão frágeis garantias (SALVADOR, 2008).

Cabe chamar a atenção para o fato de que ocorreram mudanças na condução desse processo de contrarreforma tributária, no sentido de assegurar um processo mais ágil e nebuloso. Diante da dificuldade de aprová-la por meio de texto único, o tom adotado no atual governo está fundado na perspectiva de fomentar pequenas reformas de cunho gerencial, com vistas à simplificação e à racionalização do sistema, conforme expresso em seu discurso proferido durante a posse presidencial.

Com isso, o Plano Brasil Maior, lançado em agosto de 2011, prevê uma série de ações que asseguram o fortalecimento da indústria brasileira em tempos de crise, em detrimento da condição do trabalho. 
Uma das medidas refere-se à desoneração da contribuição patronal sobre a folha de pagamento dos setores de confecção, calçados, móveis e software até o final de 2012 e, consequentemente, a acentuação da incidência tributária sobre a renda dos trabalhadores. Essa ação - empregada sob as equivocadas justificativas de alto custo da força de trabalho no Brasil, da competitividade produtiva, de impacto zero na previdência e da criação de postos de emprego - atinge visceralmente o orçamento e a concepção de direito à seguridade social, particularmente o da previdência social. Estima-se a perda de recursos para a seguridade social na ordem de $\mathrm{R} \$ 200$ milhões, em 2011, e de R\$ 1,4 bilhão, em 2012 (RECEITA..., 2011).

A proposta apresentada pelo governo para a recomposição do recurso da seguridade social acentua a lógica tributária regressiva, pois a tributação sobre a folha de pagamentos foi substituída pela contribuição sobre o faturamento e, eventualmente, por recursos do Tesouro. Trata-se, em outros termos, de responsabilizar integralmente o trabalhador pelo financiamento da previdência social.

\section{O FINANCIAMENTO DA SAÚDE DENTRO DA SEGURIDADE SOCIAL E A EC N²9}

Na divisão dos recursos dentro da seguridade social, a Constituição não definiu percentuais para cada política, bem como não definiu, no caso da saúde, como se daria a participação de cada esfera de governo - municipal, estadual e federal - no seu financiamento.

Em relação à primeira questão nas disposições transitórias da Constituição, garantia-se, pelo menos, 30\% dos recursos do orçamento da seguridade social para a saúde. Esse dispositivo cessou em 1990, com a aprovação da Lei $n^{\circ} 8080$, lei que regulamentou o SUS. No ano seguinte, os recursos para a saúde já haviam se reduzido para 20,95\% (MARQUES; MENDES, 2005, p. 164). Os constrangimentos no total de recursos para a seguridade social têm impactado mais ainda o orçamento da saúde, mas voltaremos a esse ponto nos próximos itens.

Sobre a segunda questão, apenas em 13 de setembro de 2000, 10 anos, portanto, após a promulgação da lei de regulamentação do SUS e a adoção de respostas temporárias (como a CPMF), foi apro- 
vada a Emenda Constitucional $n^{\circ} 29$ (BRASIL, 2000), estipulando a forma de inserção da União, dos estados e dos municípios no financiamento do SUS. A Emenda Constitucional (EC) $n^{\circ} 29$ tinha o intuito de prover a suficiência de recursos, bem como avançar no que concerne à solidariedade federativa, ao estabelecer parâmetros para as relações fiscais intergovernamentais dentro do SUS.

A EC $n^{\circ} 29$ definia que os estados e municípios deveriam, inicialmente, alocar no mínimo $7 \%$ das suas receitas na área da saúde, e, até o ano de 2004 , atingir o mínimo de $12 \%$, no caso dos estados, e $15 \%$, no caso dos municípios. A União deveria no primeiro ano ampliar em $5 \%$ o orçamento do ano anterior e, a partir daí, corrigir todos os anos o orçamento da saúde pela variação do PIB. No entanto, a despeito da conquista que foi a aprovação da $E C n^{\circ} 29$, ao estabelecer a vinculação de recursos, considerando as três esferas de governo, e ao garantir e reforçar o papel de controle e fiscalização dos Conselhos de Saúde, não definiu, porém, qual é a origem dos recursos e foi omissa em relação ao percentual de cada política na seguridade, ignorando a existência de disputa nesse âmbito.

É importante registrar que nenhuma das esferas governamentais cumpriu a vinculação prevista. No nível federal, o Ministério do Planejamento considerou como ano-base para o cálculo da EC n²9 o ano de 1999 e não o de 2000, como defendia o Ministério da Saúde, o que significou uma redução de 1,19 bilhões de reais no orçamento de 2001, além das perdas que se acumularam nos reajustes seguintes. Nos estados, observa-se que o percentual mínimo não tem sido aplicado em muitos casos. Somando os orçamentos estaduais, até 2002 foram aplicados 3,6 bilhões de reais a menos do que é garantido pela $E C \mathrm{n}^{\circ} 29$. Nos municípios, apesar do percentual mínimo estar sendo aplicado, o que era para ser o piso transformou-se em teto, isto é, os recursos mínimos não se ampliam, mesmo quando as necessidades locais são maiores (MARQUES; MENDES, 2005).

Outro problema que vem sendo verificado no cumprimento dos percentuais mínimos é que, em todos os níveis de governo, para burlar a $E C n^{\circ} 29$, passou-se a considerar ações de saúde uma série de gastos como saneamento básico, merenda escolar, pagamento de inativos, entre outros, apesar da Resolução $n^{\circ} 322$, de 
2003 do CNS estabelecer o que são despesas de ações e serviços de saúde (CONSELHO NACIONAL DE SAÚDE, 2003).

O que se observa é que, apesar de todo o esforço, o SUS continua subfinanciado, representando menos de $17 \%$ do Orçamento da Seguridade Social (OSS) e cerca de $5 \%$ da despesa efetiva do governo federal (DAIN, 2007, p. 1854).

\section{O FINANCIAMENTO DA SAÚDE PÓS-CONSTITUIÇÃO DE 1988: OS DILEMAS DA DESCENTRALIZAÇÃO E A PRIVATIZAÇÃO POR DENTRO DO SUS}

A partir da Constituição de 1988, através de articulação, mobilização e luta de trabalhadores e usuários da saúde, foi elaborado o SUS, marcado pelos princípios de universalidade, equidade, integralidade, descentralização político-administrativa e participação social, integrante da seguridade social e financiado por este orçamento.

A descentralização político-administrativa significava uma maior responsabilização, sobretudo dos municípios na gestão da saúde. No entanto, financeiramente, permanecia a dependência da União, na medida em que a arrecadação das contribuições sociais continuava centralizada nessa esfera de governo. Além disso, é preciso considerar que o Brasil é um país extremamente desigual e heterogêneo, podendo ser encontradas realidades muito diversas em seus mais de 5.500 municípios. A Norma Operacional Básica SUS (NOB- 01/1993) é um marco na política de descentralização, uma vez que a participação dos municípios no financiamento do SUS passou de $17,2 \%$, em 1994, para 21,3\%, em 2001 (MARQUES; MENDES, 2005).

Apesar de a esfera federal ter aplicado o maior montante de recursos no SUS (sua participação total em 2001 era de 56,4\% do total de recursos), foi o ente federado que menos ampliou a aplicação de recursos no período. No período de 1995 e 2004, o gasto federal em saúde aumentou apenas 1,3\%, o gasto estadual cresceu 19,1\% e o gasto municipal 55,8\% (BANCO MUNDIAL, 2007).

Além disso, a NOB 01/93 (BRASIL, 1993) garantiu a transferência regular e automática de recursos do Fundo Nacional de Saúde para os Fundos Municipais de Saúde, as chamadas transferências fun- 
do-a-fundo, garantindo autonomia de aplicação dos recursos aos municípios habilitados. Essa habilitação para gestão plena do SUS requer a existência de planos de saúde, conselhos municipais de saúde e relatórios de gestão que permitam o controle social, fundo de saúde, contrapartida de recursos do orçamento local e comissão para elaboração do Plano de Cargos, Carreira e Salários (PCCS) dos funcionários da saúde.

As transferências fundo-a-fundo, no entanto, não garantiram, na prática, a autonomia dos municípios na aplicação dos recursos, pois cada vez mais o governo federal repassava recursos carimbados, isto é, destinados a programas definidos previamente, que não podiam ser designados para outros fins, impedindo os municípios de discutirem localmente a melhor utilização dos recursos (MARQUES; MENDES, 2005).

Dain (2007, p.1856) indica ainda que, mesmo após 1988, não foram propostos critérios claros para a descentralização. Assim, "[...] os critérios de repasse não levam em conta as carências na oferta de serviços 'públicos' e visam apenas à equalização de rendas, havendo uma ausência de territorialidade no pacto federativo brasileiro, além de um conceito regional inadequado".

A lógica de transferência fundo-a-fundo deveria se firmar, a partir da NOB 93 e da NOB 96, como alternativa à lógica de remuneração por serviço produzido. Contudo, a remuneração por procedimento ou serviço produzido tornou a opção pela contratação de terceiros, isto é, da saúde privada complementar ${ }^{9}$, ao invés da estruturação própria de serviços pela esfera pública, politicamente mais rentável e rápida para os municípios (BATISTA JUNIOR, 2010). Isso aprofundou a ideia da saúde como um negócio extremamente lucrativo, construindo uma lógica de privatização por dentro do SUS que fortaleceu a saúde privada. Segundo dados do Fórum de Saúde de Alagoas, atualmente, mais da metade dos recursos do SUS é drenada para

\footnotetext{
9 Segundo a Lei $n^{\circ} 8.080$, de 1990, que regulamenta o SUS, no título III, que versa sobre os serviços privados de assistência à saúde, no capítulo II - da participação complementar: "[...] quando as suas disponibilidades forem insuficientes para garantir a cobertura assistencial à população de uma determinada área, o Sistema Único de Saúde (SUS) poderá recorrer aos serviços ofertados pela iniciativa privada. [...] A participação complementar dos serviços privados será formalizada mediante contrato ou convênio, observadas, a respeito, as normas de direito público" (BRASIL, 1990).
} 
o pagamento de procedimentos em serviços privados contratados, caracterizando uma "complementaridade às avessas".

Para ilustrar a questão da privatização do SUS, no que tange à política de pessoal, tomamos informações a respeito do estado do Amazonas em 2007 (SOUZA, 2009), mas que se repetem em vários outros estados da federação, quanto à utilização de cooperativas de saúde para a prestação de serviços de saúde. O valor destinado às cooperativas (181 milhões de reais) é quase a metade do destinado ao pagamento dos servidores públicos e encargos da saúde (483 milhões de reais). Isso sem considerar outras formas de contratação, que se somadas superam a folha de pagamentos do estado. Vale dizer que o estado do Amazonas tem um quantitativo de 15 mil servidores, ao passo que o pagamento das cooperativas é destinado a 1.900 cooperados.

Além disso, as tarefas exercidas pelos médicos e profissionais contratados por meio das cooperativas normalmente correspondem às funções de cargos públicos, sem contar que traduzem atividade-fim na área da saúde.

A terceirização de mão-de-obra para exercer atividade inerente ao quadro de pessoal viola o art. 37, II, da Constituição Federal e os princípios da isonomia e moralidade. A Justiça Trabalhista rotineiramente tem atribuído ao Estado do Amazonas responsabilidade subsidiária, ao considerar que as cooperativas encobrem uma contratação irregular (AMAZONAS, 2006, p. 166).

O caso, levado ao Tribunal de Contas da União (TCU), foi julgado procedente:

Na realidade, referidas Cooperativas estão desempenhando, em relação aos serviços municipais de saúde, o mesmo papel que desempenham as fundações de apoio [...]: elas vivem exclusivamente em função do vínculo com o Município; não têm patrimônio próprio; utilizam as instalações públicas com todos os equipamentos públicos; grande parte dos cooperados são servidores públicos afastados ou exonerados, que apenas mudam o título sob o qual prestam o serviço e deixam de se submeter às normas constitucionais e infraconstitucionais sobre servidores públicos; seus salários também não 
sofrem mais as limitações constitucionais próprias dos servidores; já não estão sujeitos à proibição de acumular cargos, empregos e funções; não mais oneram a folha de pagamento de servidores do Município; no entanto, continuam a receber salários provenientes dos cofres públicos; deixa de aplicar-se a lei de licitações e contratos (DI PIETRO apud AMAZONAS, 2006, p. 168).

\section{O RETORNO DO DEBATE ACERCA DA EMENDA 29 E A PROPOSTA DA CSS}

No segundo semestre de 2011, a possibilidade de votar um projeto de lei para regulamentar a EC 29 recolocou o debate do financiamento da saúde na agenda pública. O projeto de lei que foi emendado e debatido é o Projeto de Lei do Senado (PLS), $n^{\circ}$ 121/07, de autoria do Senador Tião Viana (PT- AC), remetido à Câmara de Deputados como Projeto de Lei e outras Preposições (PLP), $\mathrm{n}^{\circ}$ 306/2008. Segundo a Lei da EC 29 de 2000, ela deveria ser regulamentada em 2004, mas o projeto em discussão é de 2007, ou seja, já faz quatro anos que o projeto está em tramitação. Só em 2011, por iniciativa do governo federal, o projeto foi votado em regime de urgência ${ }^{10}$. O PL original trazia dois avanços importantes: a fixação da participação da União em 10\% de sua receita bruta e a regulamentação do que são ações de saúde, limitando-as ao âmbito do SUS, excluindo gastos com assistência social, merenda escolar, saneamento básico, aposentadoria dos profissionais da saúde, entre outras ações que vinham sistematicamente retirando recursos do SUS, maquiando a aplicação dos percentuais mínimos. Estima-se que, com a aprovação desse percentual, a saúde ganharia 32,5 biIhões de reais (CARVALHO, 2011). Observa-se, ainda, que o projeto garantia a transparência e a fiscalização por meio dos Conselhos de Saúde, mas sem incorporar dispositivos atinentes à correção da distribuição desigual dos recursos entre as regiões do país.

Nesse processo, uma das principais polêmicas, uma emenda não aprovada, propunha a criação da CSS, que ressuscitaria a CPMF. A emenda

10 O projeto foi votado no Congresso no segundo semestre de 2011 e sancionado por Roussef com 15 vetos em 15 de janeiro de 2012. 
garantia que a totalidade dos recursos arrecadados com esse novo-veIho imposto iria para o Fundo de Saúde, excetuando os 20\% da DRU. À primeira vista, a criação dessa fonte de recurso específica para a saúde significaria a possibilidade de aumento de recursos para essa política. Entretanto, significaria, também, reforçar o caráter de especialização, e não de diversificação, das receitas que financiam as políticas de seguridade social. Ou seja, esses recursos não poderiam custear, por exemplo, a ampliação da previdência rural.

Outra emenda, essa aprovada, tirou os recursos do Fundeb da base de cálculo dos percentuais mínimos. Estima-se que significará uma perda de $\mathrm{R} \$ \mathrm{~T}$ bilhões de reais anuais para a saúde. Com isso, os recursos arrecadados pela CSS serviriam basicamente para repor os recursos perdidos com a retirada do Fundo de Manutenção e Desenvolvimento da Educação Básica e de Valorização dos Profissionais da Educação (Fundeb) da base de cálculo sobrando, apenas, 8,2 milhões de ganhos reais (CARVALHO, 2011b).

Outras propostas têm sido ventiladas para garantir os recursos necessários para a saúde, quais sejam: taxação maior de bebidas alcoólicas e cigarro, bem como multas de trânsito (elementos que, contudo, garantem uma arrecadação bastante pequena frente às necessidades da saúde); fim do desconto de despesas particulares com saúde no imposto de renda e do subsídio do Estado ao pagamento de planos de saúde dos servidores públicos; taxação das grandes fortunas (proposta que se arrasta há muitos anos no Brasil); redução em 1\% dos juros do país fixados pelo governo (que manteria 10 bilhões nos cofres públicos, a serem usados na saúde); e uso dos recursos do pré-sal, que estão sendo disputados por todas as áreas e entes da federação.

O consenso estabelecido entre os defensores do SUS é a necessidade de ampliar em $\mathrm{R} \$ 83$ bilhões dos atuais $\mathrm{R} \$$ 71,5 bilhões do orçamento de 2011, o que alcançaria cerca de 6\% do PIB para o setor - percentual usado como referência por ser aquele aplicado em média nos países centrais ${ }^{11}$. Com as propostas em discussão, municípios e estados continuarão repassando 12\% e $15 \%$.

11 Essa proposta foi consensual no II Seminário contra a privatização da saúde, organizado pela Frente Nacional contra a privatização da saúde, em 2011, São Paulo, a partir de palestra proferida pelo Prof. Áquilas Mendes. 
O que está em debate é a necessidade de ampliação dos recursos federais. Sem os $10 \%$ da receita bruta, presentes no projeto original, porém recusado pelo Congresso e pelo governo federal, e com a retirada do Fundeb da base de cálculo, a saúde perdeu com a regulamentação da EC 29. A única possibilidade era a aprovação da CSS, imposto regressivo, que deixaria a saúde praticamente na mesma situação que se encontra hoje. Essa saída teve várias resistências dos parlamentares e da população, na medida em que significa a criação de um novo imposto. Ou seja, estamos discutindo "[...] um museu de grandes novidades [...]". ${ }^{12}$

Para Gilson Carvalho, da Comissão de Financiamento do Conselho Nacional de Saúde:

Não se pode cair na falácia da planieconomocracia governamental, afirmando que gasta-se muito e gasta-se mal. Convencermo-nos, calibrando o discurso verdadeiro do: gasta-se pouco e gasta-se mal (mau uso e uso errado). Além de medidas eficientizadoras, as mais diversas, há necessidade de mais recursos para a saúde (CARVALHO, 2011a, não paginado).

A ampliação de recursos para a saúde passa necessariamente pelo questionamento de prioridades da política econômica e de ameaças à privatização do SUS. Trata-se de discutir a rigidez e a blindagem impressa às medidas econômicas, que consistem em comprometer metade do orçamento com pagamento da dívida e adotar altos juros, DRU, superavit primário e demais mecanismos que tendem a beneficiar majoritariamente o capital financeiro, como vimos anteriormente, bem como as medidas de privatização camuflada da saúde. São medidas que em momentos agudos da crise do capital têm no fundo público o caminho para socializar cada vez mais os custos e os prejuízos, bem como aumentar a apropriação privada da riqueza. A seguir, veremos mais especificamente a importância da luta pela ampliação de recursos ser acompanhada pelo debate sobre a gestão dos serviços ofertados pelo SUS.

12 Trecho da música O tempo não para, do cantor e compositor Cazuza. 


\section{FINANCIAMENTO E NOVOS MODELOS DE GESTÃO: NOVOS ME- CANISMOS DE APROPRIAÇÃO DO FUNDO PÚBLICO}

Em torno do debate sobre a EC n ${ }^{\circ} 29$, articulou-se um grupo de mobilização chamado Primavera da Saúde. Na organização deste movimento, estavam a Central Única dos Trabalhadores (CUT), a Central dos Trabalhadores e Trabalhadoras do Brasil (CTB) e o Centro Brasileiro de Estudos de Saúde (Cebes), além de outros movimentos sociais ligados ao Partido dos Trabalhadores (PT) e ao Partido Comunista do Brasil (PCdoB), partidos da base do governo e inúmeros conselheiros de saúde. O movimento iniciado no Conasems realizou atos e mobilizações em defesa da regulamentação da EC $n^{\circ} 29$, mas em seu manifesto não fica claro sob que bases se daria essa regulamentação (SEJA..., 2011) 13. Além disso, a discussão do financiamento é feita por esses movimentos sem articular uma crítica frontal aos novos modelos de gestão. Por que isso é fundamental?

Esses novos modelos - organizações sociais, fundações públicas de direito privado, empresas públicas - significam, na prática, uma entrega do patrimônio do SUS para o setor privado, numa lógica de empresariamento da saúde. Por esse mecanismo, o Estado firma contratos de gestão com esses entes geridos pelo direito privado, repassando para eles recursos do fundo público em troca da prestação de serviços. No caso das organizações sociais, o processo é ainda mais escandaloso, pois dispensa concurso público para a contratação de profissionais e licitação para a compra de material.

Machado (2002) vai apontar que, nos últimos anos, houve uma verdadeira avalanche de modelos alternativos à administração estatal direta, ganhando cada vez mais visibilidade e que envolvem novas formas de gestão hospitalar, inserção e remuneração dos profissionais de saúde que podem ocorrer a partir da:

- Transformação de hospitais estatais em unidades de direito privado, com maior autonomia, dentro ou fora do aparelho do Estado;

- Criação de entidades de direito privado, paralelas aos hospitais, como as fundações privadas de apoio;

13 Ver Manifesto da Primavera da Saúde em: Seja... (2011). 
- Terceirização da gestão de unidades hospitalares públicas, através da transferência da gestão dos hospitais estatais para entes provados lucrativos ou não lucrativos;

- Terceirização das atividades assistenciais do hospital, através da terceirização de determinados serviços clínicos dentro de um hospital público ou da substituição do profissional de saúde/servidor público por prestadores organizados em modalidades privadas como as cooperativas de profissionais de saúde;

- Adoção de incentivos financeiros para os profissionais de saúde que são servidores públicos, como os vinculados à produtividade.

Com esses novos modelos, a apropriação do fundo público para entidades privadas se dá diretamente por meio do acesso ao recurso público obtido pela venda de serviços da política de saúde realizada pelo Estado. Com a redução da fiscalização e dos mecanismos de controle social, a tendência é que o aumento dos recursos do orçamento para a saúde seja canalizado para o aumento lícito e ilícito de lucros. O documento Contra fatos não há argumentos que sustentem as organizações sociais no Brasil, organizado pela Frente Nacional contra a Privatização da Saúde $(2011)^{14}$, denuncia: inúmeras fraudes trabalhistas, de compras de equipamentos e de desvio de dinheiro; o aumento de recursos destinado a esses modelos de gestão sem o correspondente crescimento da oferta de serviços; a ausência de critérios na seleção de instituições a serem contratadas; o alto custo financeiros dos contratos de gestão; o descompromisso com a continuidade do serviço prestado; o assédio moral aos trabalhadores. Em decorrência dessas práticas, a maioria das organizações sociais encontra-se sob investigação do Ministério Público.

É importante salientar que, não obstante notório conhecimento dos fatos acima citados, nos dias 13 e 15 de setembro de 2011, no

14 Articulação de movimentos sociais e partidos políticos (Partido Socialismo e Liberdade (PSOL), Partido Comunista Brasileiro (PCB) e Partido Socialista dos Trabalhadores Unificado (PSTU), setores do PT e do Pc doB) que se posicionam contra todas as formas de gestão baseadas na terceirização para pessoas jurídicas de direito privado. Ver documento: Frente Nacional Contra a Privatização da Saúde (2011). 
estado do Rio de Janeiro e na cidade de João Pessoa, foram aprovados projetos de Lei, permitindo a transferência da gestão de serviços públicos de saúde para Organizações Sociais (OS) (NO RJ..., 2011) - apesar de várias manifestações contrárias a sua aprovação, por parte de sindicatos, movimentos sociais, fóruns populares e servidores públicos. No caso do Rio de Janeiro, os manifestantes foram impedidos de entrar na Assembleia Legislativa do Estado do Rio de Janeiro (Alerj) para assistirem à votação, sendo atacados com virulência pela tropa de choque da Polícia Militar. Segue, porém, no STF, a Ação Direta de Inconstitucionalidade (Adin) n 1.923, de 1998 que torna inconstitucional a terceirização da gestão de serviços e bens coletivos para as entidades privadas.

Mas o governo segue instituindo novas formas de transferência da gestão da saúde para organizações de direito privado, como é o caso da recém-criada Empresa Brasileira de Serviços Hospitalares (EBSERH), para administrar os hospitais universitários federais ${ }^{15}$.

\section{CONSIDERAÇÕES FINAIS}

Com as breves análises e os dados apresentados no texto, temos, em síntese, duas questões-chave para compreender na sua totalidade os problemas de financiamento da seguridade social e, dentro dela, da política de saúde: por um lado, a lógica regressiva do sistema tributário faz com que as políticas sociais sejam financiadas pelos trabalhadores; por outro, tem-se observado uma estagnação nos gastos com políticas sociais em favor da transferência do fundo público para o capital por intermédio da dívida pública.

No caso da saúde, a lógica de financiamento tem historicamente beneficiado o setor privado, que recebe do SUS por meio do pagamento de procedimentos realizados pela rede contratada. Coopera para isso o espírito contrarreformista do Estado brasileiro em sua versão neoliberal, que propõe, em termos gerais, preparar o país para um novo "projeto de modernidade". Segundo este, as conquistas advindas da Constituição - principalmente seu capítulo sobre a seguridade social - deveriam ser doravante desconsideradas, uma vez que, oriundas de uma Constituição perdulária, não

15 Para aprofundar o debate sobre a EBSERH, consultar Cislaghi (2011). 
poderiam logicamente ser sustentáveis. Dá lugar, assim, a um processo de contrarreforma, que se manifesta nos discursos e ações políticas, ocasionando um verdadeiro desmonte de direitos sociais, iniciado no governo Collor de Mello e que, por sua vez, se aprofunda. Mais recentemente, os problemas gerados pelo subfinanciamento, pela falta de força de trabalho capacitada, bem remunerada e com dedicação exclusiva, que sucateiam os serviços públicos, reduzindo sua qualidade, têm sido utilizados como justificativa para a implementação de novos modelos de gestão, que transferem ainda mais recursos públicos para a iniciativa privada.

A privatização do público, mediante a racionalização e modernização da gestão, cuja proposta de mecanismo legal abrange não só a saúde, mas também a cultura, a assistência social, o lazer, entre outros serviços públicos, atinge duramente a concepção de direito social. Assim, a tendência é, além de excluir esse tipo de gestão do controle democrático, reduzir a quantidade e a qualidade dos serviços e concentrar a oferta dos serviços de saúde nas regiões ricas do país, com o objetivo de maximizar as taxas lucrativas. Recentemente aprovadas nos estados do Rio de Janeiro e da Paraíba legislações que fomentam esses modelos de gestão na administração pública, a saúde nas capitais desses estados passará a ser gerida pela lógica do mercado, do lucro, e não mais do direito social.

A solução dos problemas da saúde pública no Brasil passa pela recomposição do seu orçamento e pela efetiva implementação do SUS público e universal - e não por mais privatização e favorecimento do capital em detrimento das necessidades sociais da população trabalhadora.

Por fim, a regulamentação da Emenda Constitucional 29, apesar de necessária, não resolve a situação da insuficiência de recursos. As discussões com relação às fontes de financiamento também têm gerado polêmicas em torno da criação da CSS, que, ao que tudo indica, já foi retirada da pauta do governo diante da conjuntura não favorável à criação de mais um imposto. O fato é que retornamos ao velho argumento da escassez para explicar as escolhas políticas e econômicas; escamoteando assim, a disputa cada vez mais acirrada pelo fundo público. Infelizmente, 
se para a presidente Dilma Roussef é inaceitável aplicar 10\% da receita federal na saúde ${ }^{16}$, não é igualmente inaceitável, porém, que mais de $50 \%$ do orçamento financie, por meio de juros, o capital financeiro.

\section{REFERÊNCIAS}

ALVARENGA, Darlan. Carga tributária foi de 35\% do PIB em 2010, diz instituto. G1 economia, Rio de Janeiro, 3 mar. 2011. Disponível em: <http://g1.globo.com/economia/noticia/2011/03/carga-tributaria-foi-de-3513-do-pib-em-2010-diz-instituto.html>. Acesso em: 16 set. 2011.

AMAZONAS (AM). Tribunal de Contas. Relatório e parecer prévio sobre a prestação de contas do governo do estado do Amazonas. Manaus, 2006.

AUDITORIA CIDADÃ DA DÍVIDA. Orçamento Geral da União - 2010 - Total: R\$ 1, 414 trilhão. 2010. Disponível em: <http://www.divida-auditoriacidada.org.br/config/artigo.2011-03-02.0541123379/document_view>. 1 gráfico, color.

BANCO MUNDIAL. Governança no Sistema Único de Saúde (SUS) do Brasil: melhorando a qualidade do gasto público e gestão de recursos. Brasília: Banco Mundial, 2007. Disponível em: <http://siteresources.worldbank.org/BRAZILINPOREXTN/Resources/38171661185895645304/4044168-1186326902607/19GovernancaSUSport. pdf>. Acesso em: 1 fev. 2011.

BATISTA JR., Francisco. Gestão do SUS: o que fazer? Brasília: ConseIho Nacional de Saúde, 2010. Disponível em: <http://conselho.saude.gov.br/webfdp/gestaonosus.pdf>. Acesso em: 1 fev. 2011.

BEHRING, Elaine Rossetti. A lógica do financiamento da Seguridade Social entre 1997 e 2007. In: CONGRESSO MUNDIAL DE SERVIÇO SOCIAL, 2008. Anais.... Salvador: IASSW/ICSW/IFSW, 2008.

BEHRING, Elaine Rossetti; BOSCHETTI, Ivanete. Política Social: fundamentos e história. São Paulo: Cortez, 2006.

16 “[...] 10\% é inaceitável [...]”: foi a declaração dada pela presidente na ocasião dos debates sobre a regulamentação da EC 29 (MONTEIRO, 2011, não paginado). 
BNDES. Relatório Anual 2009. Rio de Janeiro, 2010. Disponível em: <http://www.bndes.gov.br/SiteBNDES/export/sites/default/ bndes_pt/Galerias/Arquivos/empresa/RelAnual/ra2009/relatorio_ anual2009.pdf $>$.

BRASIL. Constituição (1988). Proposta de Emenda Constitucional $n^{\circ} 233$, de 2008. Disponível em: <http://www.camara.gov.br/proposicoesWeb/fichadetramitacao?idProposicao=384954>.

BRASIL. Emenda Constitucional $n^{\circ} 29$, de 13 de setembro de 2000. Altera os arts. 34, 35, 156, 160, 167 e 198 da Constituição Federal e acrescenta artigo ao Ato das Disposições Constitucionais Transitórias, para assegurar os recursos mínimos para o financiamento das ações e serviços públicos de saúde. Disponível em: <http://www. planalto.gov.br/ccivil_03/constituicao/emendas/emc/emc29.htm>.

BRASIL. Lei $n^{\circ} 8.080$, de 19 de Setembro de 1990. Dispõe sobre as condições para a promoção, proteção e recuperação da saúde, a organização e o funcionamento dos serviços correspondentes e dá outras providências. Disponível em: <http://portal.saude.gov.br/ portal/arquivos/pdf/lei8080.pdf>.

BRASIL. Ministério da Saúde. Portaria GM/MS n 545, de 20 de maio de 1993. Estabelece normas e procedimentos reguladores do processo de descentralização da gestão das ações e serviços de saúde, através da Norma Operacional Básica - SUS 01/93. Disponível em: <http://bvsms.saude.gov.br/bvs/saudelegis/gm/1993/ prt0545_20_05_1993.html>.

CARVALHO, Gilson. Domingueira: nós e perspectivas da Regulamentação da EC-29. 11 set. 2011a. Disponível em: < http://blogsaudebrasil.com.br/2011/09/11/domingueira-nos-e-perspectivas-da-regulamentacao-da-ec-29/>. Acesso em: 16 out. 2011.

CARVALHO, Gilson. Domingueira: financiamento da saúde. $6 \mathrm{dez}$. 2011b. Disponível em: <http://blogsaudebrasil.com.br/2011/12/06/ domingueira-financiamento-da-saude/>.

CISLAGHI, Juliana Fiuza. Hospitais Universitários Federais e novos modelos de gestão: faces da contrarreforma do Estado no Brasil. In: BRAVO, Maria Inês Souza; MENEZES, Juliana Souza Bravo. Cadernos de Saúde. Rio de Janeiro: ADUFRJ, 2011. 
CONSELHO NACIONAL DE SAÚDE (Brasil). Resolução n 322, de 8 de maio de 2003. Disponível em: <http://conselho.saude.gov.br/ reרsolucoes/reso_03.htm>.

DAIN, Sulamis. Os vários mundos do financiamento da saúde no Brasil: uma tentativa de integração. Ciência \& Saúde Coletiva, Rio de Janeiro, v. 12, p. 1851-1864, 2007. Disponível em: <http://www. revista.epsjv.fiocruz.br//include/mostrarpdf.cfm?Num=229>. Aces-so em: 10 dez. 2007.

FRENTE NACIONAL CONTRA A PRIVATIZAÇÃO DA SAÚDE (Org.). Contra fatos não há argumentos que sustentem as Organizações Sociais no Brasil: relatório analítico de prejuízos à sociedade, aos trabalhadores e ao erário por parte das Organizações Sociais (OSs). 2011. Disponível em: <http://pelasaude.blogspot.com.br/p/contra-fatos-nao-ha-argumentos-que.html>. Acesso em: 1 ago. 2012.

GENTIL, Denise Lobato. A política fiscal e a falsa crise do sistema de seguridade social no Brasil: análise financeira do período recente. In: SíCSU, João. (org.) Arrecadação de onde vem? E gastos públicos para onde vão? São Paulo: Boitempo, 2007.

IMPOSTO sobre consumo lidera a carga tributária. Clipping: noticias do dia, São Paulo, 8 jul. 2009. Disponível em: <http://www.portogente.com.br/texto.php?cod=23650>.

MACHADO, Cristiani. Novos modelos de gestão hospitalar. 2002. (Desenvolvimento de material didático ou instrucional - Capítulo de Livro).

MARQUES, Rosa Maria; MENDES, Áquila. Os dilemas do financiamento do SUS no interior da seguridade social. Economia e Sociedade, Campinas, v. 14, n. 1, p. 159-175, jan./ jun.2005. Disponível em: <http://www.eco.unicamp.br/docdownload/publicacoes/instituto/ revistas/economia-e-sociedade/V14-F1-S24/07-RosaAquilasMendes. pdf >. Acesso em: 1 fev. 2011.

MONTEIRO, Tânia. Para Dilma, 10\% para saúde é? Inaceitável? Isto é Dinheiro Online, Santo Amaro (SP), 26 set. 2011. Disponível em: <http://www.istoedinheiro.com.br/noticias/67583_ PARA+DILMA+10+PARA+SAUDE+ E+INACEITAVEL>. Acesso em: 30 set. 2011. 
NO RJ e na PB, saúde pública é violentada. 17 set. 2011. Disponível em: <http://www.cfess.org.br/noticias_res.php?id=687>. Acesso em: 18 set. 2011.

OLIVEIRA, Francisco de. Os direitos do antivalor: a economia política da hegemonia imperfeita. Petrópolis: Vozes, 1998.

PIOLA, Sérgio Francisco. Entrevista para o Valor Econômico. [2009]. Disponível em: <http://www.valor.com.br/sites/default/files/valor___entrevista_piola.pdf >. Acesso em: 16 set. 2011.

RECEITA estuda tributo para compensar desoneração da folha de pagamentos. Correio Braziliense, Brasília, 3 ago. 2011. Disponível em: <http://www.correiobraziliense.com.br/app/noticia/economia/2011/08/03/internas_economia, 263900/receita-estuda-tributo-para-compensar-desoneracao-da-folha-de-pagamentos.shtml>. Acesso em: 10 ago. 2011.

SALVADOR, Evilasio. A distribuição da carga tributária: quem paga a conta? In: SícSU, João. (Org.) Arrecadação de onde vem? E gastos públicos para onde vão? São Paulo: Boitempo, 2007. Disponível em: <http://www.direitosociais.org.br/_arquivos/2009/223_distribuicao_da_carga_tributaria.pdf >. Acesso em: 1 fev. 2011.

- Reforma tributária desmonta o financiamento das políticas sociais (nota técnica). Brasília: INESC, 2008. Disponível em: <http:// www.inesc.org.br/biblioteca/publicacoes/artigos/brasil-reforma-tributaria-desmonta-o-financiamento-das-politicas-sociais>. Acesso em: 1 fev. 2011.

. Fundo público e seguridade social no Brasil. São Paulo: Cortez, 2010.

SEJA bem vinda a Primavera da Saúde. 8 set. 2011. Disponível em: <http://www.cebes.org.br/verBlog.asp?idConteudo=1516\&idSubCa tegoria $=56>$.

SOUZA, Tainá. "Fazer mais e melhor com o pouco que eu tenho": um estudo da política nacional de humanização implementada em Manaus. 2009. 266f. Dissertação (Mestrado em Serviço Social) Programa de Pós-Graduação em Serviço Social da UERJ, Rio de Janeiro, 2009. Disponível em: < http://www.bdtd.uerj.br/tde_busca/ arquivo.php?codArquivo $=3364>$. 